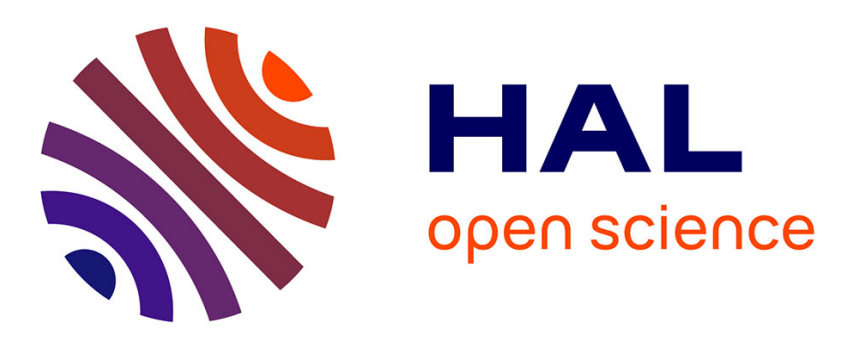

\title{
Original Bio-Based Antioxidant Poly(meth)acrylate from Gallic Acid-Based Monomers
}

Ali Khalil, Christine Gerardin-Charbonnier, Hubert Chapuis, Khalid Ferji, J.L. Six

\section{- To cite this version:}

Ali Khalil, Christine Gerardin-Charbonnier, Hubert Chapuis, Khalid Ferji, J.L. Six. Original BioBased Antioxidant Poly(meth)acrylate from Gallic Acid-Based Monomers. ACS Sustainable Chemistry \& Engineering, 2021, 9 (34), pp.11458-11468. 10.1021/acssuschemeng.1c03607 . hal-03521726

\author{
HAL Id: hal-03521726 \\ https://hal.science/hal-03521726
}

Submitted on 11 Jan 2022

HAL is a multi-disciplinary open access archive for the deposit and dissemination of scientific research documents, whether they are published or not. The documents may come from teaching and research institutions in France or abroad, or from public or private research centers.
L'archive ouverte pluridisciplinaire HAL, est destinée au dépôt et à la diffusion de documents scientifiques de niveau recherche, publiés ou non, émanant des établissements d'enseignement et de recherche français ou étrangers, des laboratoires publics ou privés. 


\section{Original Bio-based Antioxidant Poly(meth)acrylate from Gallic Acid -based Monomer}

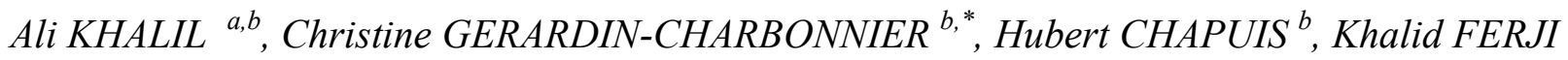
a, Jean-Luc SIX ${ }^{a, *}$

a) Université de Lorraine, CNRS, LCPM, F-54000 Nancy, France

b) Université de Lorraine, INRAE, LERMAB, F-54000 Nancy, France

Submitted to ACS Sustainable Chemistry \& Engineering

KEYWORDS: Photo-RAFT, Controlled polymerization, free radical scavenging, polyphenol, wood extractives. 


\section{ABSTRACT}

Herein, we report a multistep synthesis of novel (meth)acrylate monomers based on gallic acid (GA), a bio-sourced phenolic acid. The objective of this work was to obtain bio-based polymers exhibiting antioxidant properties provided by monomers derived from gallic acid. The phenolic groups of GA, which are responsible for antioxidant properties, need to be protected for two reasons. On the one hand, functionalization to transform GA into polymerizable monomers must not take place at the phenolic groups because they must remain free to maintain the maximum antioxidant activity in the final polymers. On the other hand, their protection is necessary to prevent radical scavenging during the radical polymerization. After synthesis of such monomers, protected GA-based polymers were thus produced through a photo-mediated RAFT polymerization at room temperature by evaluating two trithiocarbonate-type chain transfer agents (CTAs). The kinetics and the molecular weight distributions were studied depending on the monomers and the CTAs. Protected polymers were then deprotected to afford polymeric chains carrying one free gallic acid moiety on each monomer unit. Antioxidant activity of these free GA-based polymers was demonstrated either through the DPPH free radical scavenging property and through the inhibition of the methyl linoleate oxidation. 


\section{INTRODUCTION}

Secondary metabolites from plant kingdom or wood, have long been studied to harness their therapeutic properties. Indeed, according to recent studies, $25 \%$ of medicines are originated directly or indirectly from natural products. ${ }^{1-3}$ These compounds correspond to polyphenols such as flavonoids, lignans, stilbenes, phenolic acids and nor tannins. Characterized by having at least one aromatic ring with one to several hydroxyl groups, polyphenols are widely diverse structurally and functionally. ${ }^{4-6}$ Such phenolic bio-sourced compounds have been used in food applications, packaging or materials, or nor as multi-target bioactive agents against cancer and inflammation, but also in cosmetics and biofertilizers. ${ }^{7-10}$ Gallic acid (GA, Scheme 1) is the most investigated polyphenol owing to its accessibility, applications and relatively low price. It can be extracted under different forms from chestnut, nuts, sumac, gallnuts, witch hazel, clove, tealeaves and other plants. ${ }^{11}$ Moreover, it is particularly accessible via oak bark transformation industry under the form of hydrolysable tannins. ${ }^{12-13} \mathrm{GA}$ and its ester derivatives (e.g. propyl gallate, octyl gallate, and lauryl gallate) exhibit numerous properties serving as antioxidants, antimicrobials or anticancer, as well as active agents that reduce cellular oxidative stress. ${ }^{14-16}$ However, concerning biomedical applications and similar to numerous phytochemicals, harnessing the full potential of GA within the human body stumbles with its low bioavailability and bioactivity which are pivotal for any bioactive molecule to be considered efficient. ${ }^{17-19}$ To overcome these issues, drug delivery systems (DDSs) as polymeric electrospun fiber mats ${ }^{20-22}$, nanoparticles $^{23-24}$ or hydrogels ${ }^{25-28}$ have considerably grasped attention as a possible way to improve GA's pharmacokinetics.

Gallic acid, as an $\mathrm{AB}_{3}$ tetra-functional monomer, has also inspired researchers to produce crosslinked $^{29-35}$ or hyperbranched polymeric materials. ${ }^{36-38}$ Nevertheless, the conjugation of GA 
onto natural polymeric substrates has received more significant attention. Moreover, a recent review has described the chemical/enzymatic grafting of GA onto polysaccharides to broaden applications in the fields of active packaging, edible coating and DDS. ${ }^{39}$ Likewise, antioxidant properties of GA/gelatin conjugates were also reported. ${ }^{40-41}$ Surprisingly, no GA-functionalized synthetic thermoplastic polymers were described despite the potential antioxidant properties of such materials. Nevertheless, strictly speaking, we must however point out i) the grafting of enzymatic-produced poly(gallic acid) onto polycaprolactone film to provide it antioxidant property $^{42}$; and ii) gallol (1,2,3-trihydroxybenzene)-based polymers exhibiting antioxidant performances $^{43-46}$.

Since more than 30 years, many advanced and updated versions of reversible deactivation radical polymerizations (RDRP) including atom transfer radical polymerization (ATRP), nitroxide mediated polymerization (NMP), reversible addition-fragmentation chain transfer (RAFT) and few others have appeared. ${ }^{47}$ RAFT polymerization, which is one of the most versatile and capable technique for polymer synthesis, has grasped significant attention from researchers yielding up more than 11,000 publications by the end of $2020 .^{48,49}$ Photo-mediated RAFT polymerization (photo-RAFT) has recently emerged as a versatile low-energy alternative of thermal one, due to its easiness, rapidity, ability to control the polymerization of a wide range of monomers at room temperature, and to afford spatio and temporal controls of the polymerization by switching the light on and off. ${ }^{50-54}$ To the best of our knowledge, polymers issued from GA-based monomers have never been synthesized using photo-RAFT or any other RDRP mechanism. To date, only one paper reports the ring opening metathesis polymerization of GA-functionalized monomer. ${ }^{55}$ The scarcity of papers dealing with such chain polymerizations may be undoubtedly linked to the difficulty of polymerizing GA-functionalized 
monomers due to the presence of phenolic hydroxyl groups that are responsible of antioxidant property of GA. Protecting the hydroxyl group of GA before its radical polymerization can be an original way to obtain GA-based polymers via RDRP methods.

Within this framework, our focus is herein firstly devoted to the synthesis of two novel GAbased (meth)acrylate monomers. Homopolymers bearing one protected GA side group per monomer unit are then prepared from the corresponding monomers through photo-RAFT. After deprotection, GA moieties are afforded on the polymeric chains. Finally, the antioxidant activity of such novel polymers is studied using two different methods: 2,2-diphenyl-1-(2,4,6trinitrophenyl)hydrazyl (DPPH) radical scavenging assay and inhibition of methyl linoleate oxidation.

\section{EXPERIMENTAL SECTION}

\section{Materials}

Methyl gallate (1, Scheme 1) (99\%, Acros Organics) and N-(3-dimethylaminopropyl)-N'ethylcarbodiimide hydrochloride (EDC.HCl, 99\%, ABCR) were used as received. Benzyl bromide (98\%), 4-(dimethylamino)pyridine (DMAP, 99\%), 2-hydroxyethyl acrylate (96\%), 2hydroxyethyl methacrylate (99\%), N-hydroxyethyl acrylamide $(97 \%$,), palladium on carbon (Pd/C, 10 wt. \% loading), methyl linoleate (98\%), 2,2-diphenyl-1-(2,4,6-trinitrophenyl)hydrazyl (DPPH, 95\%), potassium carbonate $\left(\mathrm{K}_{2} \mathrm{CO}_{3}\right)$, potassium hydroxide $(\mathrm{KOH})$, sodium bicarbonate $\left(\mathrm{NaHCO}_{3}\right)$, magnesium sulfate $\left(\mathrm{MgSO}_{4}\right)$, filter agent Celite ${ }^{\circledR} 545$ were ordered from Merck and used as received. Dimethyl sulfoxide (DMSO, 99.7\%, Merck) was stored with molecular sieves. 
Acetone (99.8\%), dichloromethane (99.9\%), hexane (96\%) and methanol (99.9\%) were purchased from Carlo Erba, when acetonitrile (99.8\%), 1-butanol (99.8\%), ethyl acetate (99\%) were from Merck. All these solvents were used as received. Azobisisobutyronitrile (AIBN, 98\%, Merck) was recrystallized from methanol and dried overnight at $40{ }^{\circ} \mathrm{C}$ under vacuum. Chain transfer agents (CTAs, Figure 1) were prepared as previously reported. ${ }^{50,56}$ Ethyl $(2,4,6-$ trimethylbenzoyl) phenylphosphinate (TPO-L, Figure 1) was purchased from Fluorochem and used as received.

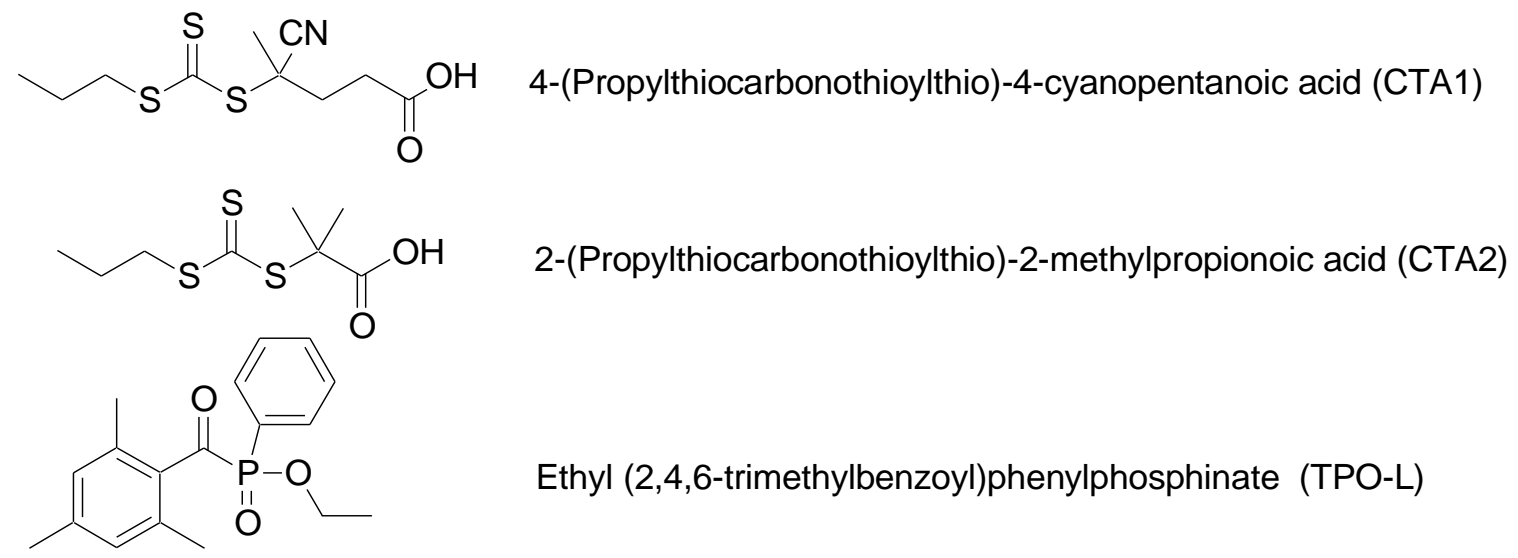

Figure 1. CTAs and photoinitiator used in the present study.

\section{Perbenzylated acrylate (BnGA-A) and methacrylate (BnGA-MA) monomers (Scheme 1)}

3,4,5-tribenzyloxybenzoic acid (3) was synthesised from methyl gallate (1) according to an improved procedure from previous reports. ${ }^{57-58}$ Accordingly, (1) was benzylated in the presence of 3.5 equivalents of benzyl bromide in mild basic conditions $\left(\mathrm{K}_{2} \mathrm{CO}_{3}\right)$ at $60^{\circ} \mathrm{C}$. Then, the benzylated compound (2) was hydrolysed in strong basic conditions (KOH) at reflux to obtain (3) with a good yield. ${ }^{1} \mathrm{H}$ NMR spectra of compounds (1), (2) and (3) are given in Figure S1. 
In a round bottom flask, 1 eq. of (3), 1.1 eq. of $\mathrm{EDC} . \mathrm{HCl}$ and 0.15 eq. of DMAP were dissolved in $200 \mathrm{~mL}$ ethyl acetate. After cooling at $4^{\circ} \mathrm{C}, 1$ eq. of 2-hydroxyethyl acrylate or 2hydroxyethyl methacrylate was slowly added. The mixture was stirred for 30 minutes, then left at room temperature. The reaction progress was monitored by thin layer chromatography (see below for used eluants), then the reaction medium was washed twice with $100 \mathrm{~mL}$ distilled water followed by saturated $\mathrm{NaHCO}_{3}$ aqueous phase. The organic phase was dried under $\mathrm{MgSO}_{4}$ then concentrated under vacuum. Pure monomers (perbenzylated acrylate (BnGA-A) and perbenzylated methacrylate (BnGA-MA)) were recovered as white powders by silica gel column purification using different eluants depending on the nature of the monomer: dichloromethane/acetone $(7 / 3 \mathrm{v} / \mathrm{v})$ was used for BnGA-A $\left(\mathrm{R}_{f}=0.78,60 \%\right.$ yield $)$ and ethyl acetate/hexane $(5 / 5 \mathrm{v} / \mathrm{v})$ for BnGA-MA $\left(\mathrm{R}_{f}=0.82,55 \%\right.$ yield $) .{ }^{1} \mathrm{H}$ NMR spectra of perbenzylated GA-based monomers are shown on Figure 2. ${ }^{13} \mathrm{C}$ NMR and FTIR spectra are given in supporting information (Figures S2 and S3, respectively).

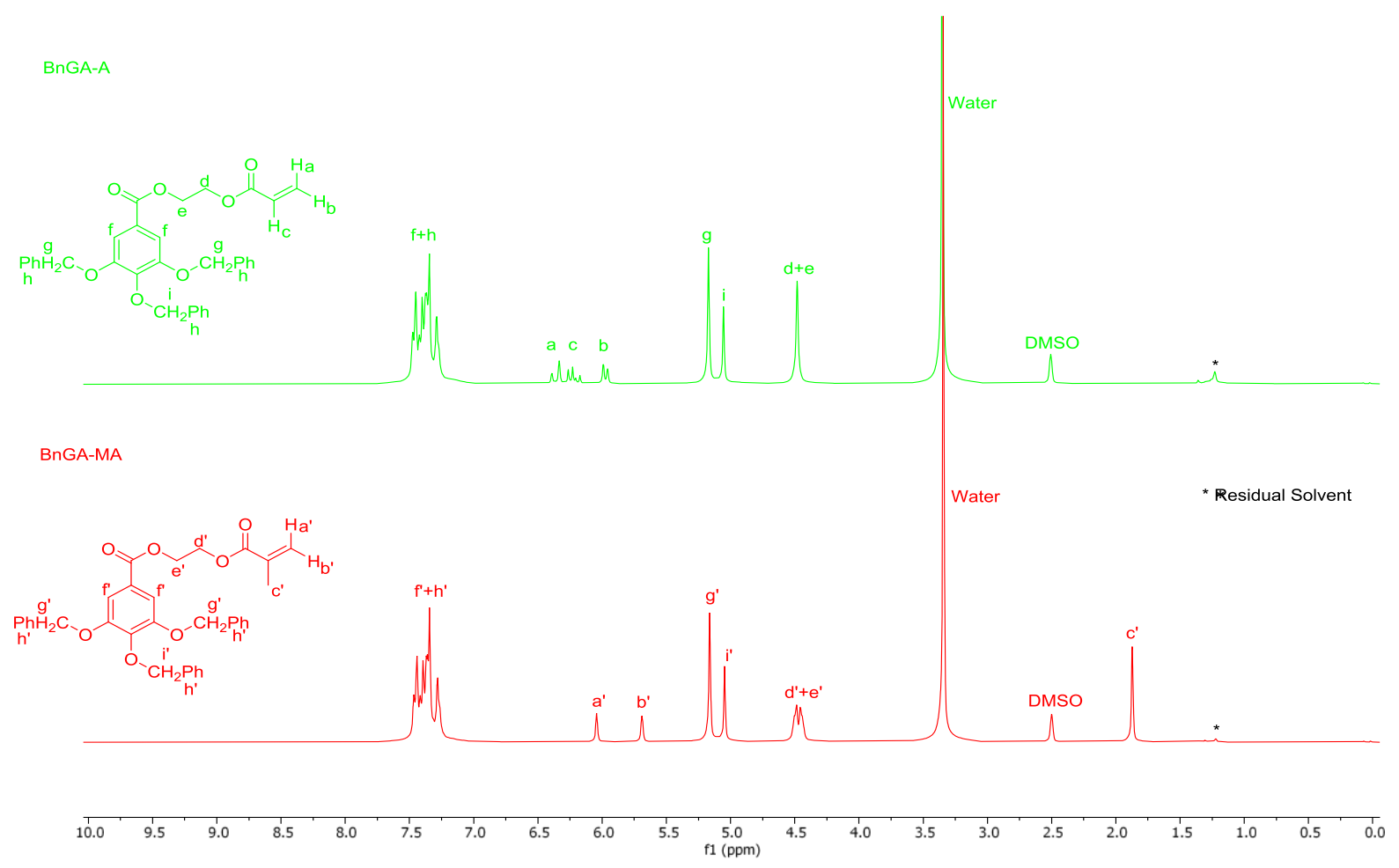


Figure 2. ${ }^{1} \mathrm{H}$ NMR spectra (DMSO- $\left.d_{6}\right)$ of BnGA-A and BnGA-MA.

\section{Polymerizations}

In a typical polymerization procedure, $500 \mathrm{mg}$ (200 eq.) of the monomer (BnGA-A or BnGAMA) were solubilized in DMSO (1 mol/mL) in a $15 \mathrm{~mL}$ vial followed by the addition of 1 eq. of AIBN in case of conventional radical polymerization. The reaction medium was purged with a continuous flow of nitrogen for $15 \mathrm{~min}$. The vial was then immersed in a thermostated oil bath at $70^{\circ} \mathrm{C}$ to initiate the polymerization. In case of photo-RAFT, 1 eq. of CTA (CTA1 or CTA2, 100 $\mathrm{mg} / \mathrm{mL}$ in DMSO) was added in the vial instead of AIBN, then 0.33 eq. of the photoinitiator TPO-L (20 mg/mL in DMSO) per CTA. After purge, the medium was finally irradiated with homemade UV-VIS LED lamp $\left(405 \mathrm{~nm}, 10 \mathrm{mWcm}^{-2}\right)$ at room temperature during maximum 2 hours to initiate and propagate the polymerization.

In each case, $200 \mu \mathrm{L}$ of the reaction medium were withdrawn under nitrogen at different time and analyzed by ${ }^{1} \mathrm{H}$ NMR and SEC. Monomer conversion (x) was determined by ${ }^{1} \mathrm{H}$ NMR according to equations given in Table S1, by comparing the peaks areas of the ethylenic protons of the monomer (from 5.60 to $6.45 \mathrm{ppm}$ ) with those of the aromatic protons (centered at 7.20 ppm) of both monomer and polymer. Example of BnGA-MA is given in Figure S4. After polymerization, crude polymers $\mathrm{P}(\mathrm{BnGA}-\mathrm{A})$ and $\mathrm{P}(\mathrm{BnGA}-\mathrm{MA})$ were precipitated from acetonitrile, then dried under vacuum at $50^{\circ} \mathrm{C}$.

\section{Hydrogenolysis of perbenzylated polymers}

$1 \mathrm{~g}$ of protected polymer was dissolved in $30 \mathrm{~mL}$ of methanol/ethyl acetate $(60 / 40, \mathrm{v} / \mathrm{v})$ at room temperature in a stainless-steel autoclave (series 4560 mini-reactor from Parr Instrument Compagny) prior to the addition of $10 \%$ wt. $\mathrm{Pd} / \mathrm{C}$. The reactor was sealed, firstly flushed with $\mathrm{N}_{2}$ 
then several times with $\mathrm{H}_{2}$, and finally placed under $\mathrm{H}_{2}$ pressure ( 25 bars). The reaction mixture was then allowed to stir at room temperature for 48 hours before the reactor was vented to atmospheric pressure. The crude mixture was then filtered through Celite by using ethanol. Dialysis in methanol was performed to purify the free GA-based polymer that is concentrated under reduced pressure to obtain greyish white solid. Dialysis membranes were purchased from Spectra Por (MWCO: 6000-8000).

\section{$\underline{\text { DPPH scavenging activity assay }}$}

Free gallic acid-based polymer stock solutions $(25 \mathrm{mM}$ of GA-based monomer units in methanol) were serially diluted to different concentrations $(5,2.5,1,0.5,0.1$, and $0.05 \mathrm{mM})$. A DPPH solution (91 $\mu \mathrm{M}$ in methanol) was freshly prepared. The polymer solutions $(30 \mu \mathrm{L})$ were added to $3 \mathrm{~mL}$ of DPPH solution and allowed to react at room temperature. The final concentrations of GA unit were $0.5,1,5,25,10,50 \mu \mathrm{M}$. Same concentrations of gallic acid were also used. After $12 \mathrm{~min}$, the absorption value $\left(\mathrm{A}_{\text {sample, }}\right.$ measured at $517 \mathrm{~nm}$ by UV-visible spectrometry) ceased to decrease. $\mathrm{A}_{\text {final }}$ is the absorption value of the DPPH solution using an excess amount of the antioxidant moieties, measured after the same reaction time. $\mathrm{DPPH} /$ methanol $(91 \mu \mathrm{M}, 3 \mathrm{~mL})$ was considered as control to determine the value of $\mathrm{A}_{\text {blank. The }}$ DPPH scavenging capacity (\% of reduction of DPPH radical) was calculated according to Eq. 1:

DPPH Radical Reduction $(\%)=\frac{A_{\text {blank }}-A_{\text {sample }}}{A_{\text {blank }}-A_{\text {final }}} \times 100$

$\mathrm{C}_{50}$ value was estimated as the concentration of antioxidant for $50 \% \mathrm{DPPH}$ scavenging by plotting DPPH radical reduction vs concentration. All experiments were performed in triplicates.

\section{Oxygen uptake method}

In a typical procedure, $1 \mathrm{~mL}$ of the antioxidant solution in DMSO $(0.8 \mathrm{mM}$ of GA or GAbased monomer unit) was introduced into a thermostatically controlled reactor. No antioxidant 
was introduced for the control assay but rather $1 \mathrm{~mL}$ of DMSO instead. $1 \mathrm{~mL}$ of methyl linoleate (1.6 $\mathrm{M}$ in 1-butanol) and $2 \mathrm{~mL}$ of AIBN (18 $\mathrm{mM}$ in 1-butanol) solutions were added, then the temperature was set to $60^{\circ} \mathrm{C}$. The reaction was continued for 2.5 hours under an initial oxygen pressure $\left(\mathrm{P}_{0}\left(\mathrm{O}_{2}\right)\right)$ of about 145 Torrs $(0.193$ bars $)$. Oxygen uptake was monitored continuously by a pressure transducer. After 2.5 hours, the amount of oxygen consumed under these conditions $\left(\Delta \mathrm{P}=\mathrm{P}_{0}\left(\mathrm{O}_{2}\right)-\mathrm{P}_{2.5}\right.$ hours $\left.\left(\mathrm{O}_{2}\right)\right)$ was compared to that consumed during the control reaction. The oxygen uptake inhibition index (OUI) is a characteristic to the antioxidative capacity of the sample and is estimated according to Eq. 2. Strong and poor antioxidants exhibit OUI values equal to $100 \%$ and $0 \%$, respectively.

OUI $(\%)=\frac{\Delta \mathrm{P}_{\text {control }}-\Delta \mathrm{P}_{\text {sample }}}{\Delta \mathrm{P}_{\text {control }}} \times 100$

\section{$\underline{\text { Instruments and measurements }}$}

${ }^{1} \mathrm{H}$, JMOD ${ }^{13} \mathrm{C}$ NMR spectra were recorded on a Bruker Advance 300 spectrometer $(300.13$ $\left.\mathrm{MHz}, 298^{\circ} \mathrm{K}\right)$ in DMSO- $d_{6}$.

Fourier-transform infrared spectroscopy (FTIR) analyses were performed on Frontier FT-IR Spectrometer Perkin Elmer with Diamond ATR module.

Molar mass distributions of perbenzylated polymers were estimated by size exclusion chromatography (SEC) in THF at $40{ }^{\circ} \mathrm{C}$ (elution rate $1 \mathrm{~mL} / \mathrm{min}$ ) equipped with a multi-angle laser light scattering detector (MALLS; Mini Dawn Treos, Wyatt), a differential refractometer detector (OPTILab Rex, Wyatt), a HPLC pump (Waters 515), a degasser AF (Waters In-Line), and three PLgel $5 \mu 1\left(10^{5}, 10^{3}\right.$, and $\left.100 \AA\right)$ columns $\left(300 \times 7.5 \mathrm{~mm}^{2}\right)$. dn/dc values of 0.185 and 0.230 were estimated for $\mathrm{P}(\mathrm{BnGA}-\mathrm{A})$ and $\mathrm{P}(\mathrm{BnGA}-\mathrm{MA})$, respectively. In case of deprotected polymers, SEC was carried out in DMSO containing $\mathrm{NaNO}_{3}(8.5 \mathrm{~g} / \mathrm{L})$ as eluent at $70{ }^{\circ} \mathrm{C}$ (elution rate $0.7 \mathrm{~mL} / \mathrm{min}$ ), equipped with a differential refractometer detector (RID 10A, Shimadzu), a 
HPLC pump (LC 20AD, Shimadzu), a degasser AF (DGU - 20A3R, Shimadzu), and three PLgel $5 \mu \mathrm{L}$ columns (see above). SEC instrument ( $\mathrm{DMSO} / \mathrm{NaNO}_{3}$ ) was calibrated with narrow linear poly(methyl methacrylate) (PMMA) standards.

UV-visible spectrometry analyses were performed using Lambda 365 UV-Vis Spectrophotometer - Perkin Elmer and quartz cuvettes.

Differential scanning calorimetry analyses (DSC) were carried out on DSC Q2000 from TA Instruments. Three cycles were successively recorded under nitrogen: the heating rate was $10^{\circ} \mathrm{C} / \mathrm{min}$ while the cooling rate was $5^{\circ} \mathrm{C} / \mathrm{min}$. The temperature was varied from $-40^{\circ} \mathrm{C}$ up to $180^{\circ} \mathrm{C}$. First cycle was used to remove all thermal history from the sample. The second heating cycle was used for determining the glass transition temperature at the inflexion point. Analysis of the data was performed using Universal ${ }^{\circledR}$ Analysis 2000 (version 4.5A) software.

Thermogravimetric Analysis (TGA) analyses were performed on a Metler Toledo TGA/DSC1TMA/SDTA 84Xe instrument by heating the polymer samples at a rate of $10^{\circ} \mathrm{C} / \mathrm{min}$ from 25 to $600^{\circ} \mathrm{C}$ under a dynamic nitrogen atmosphere (flow rate $=10 \mathrm{~mL} / \mathrm{min}$ ).

\section{RESULTS AND DISCUSSION}

\section{Perbenzylated gallic acid-based monomers}

As previously explained, GA is an efficient natural antioxidant able to rapidly inhibit radicals due to the high stability of the radical forms of $\mathrm{GA}^{59}$ We hypothesized that radical polymerization of a GA-based monomer can be very difficult. In order to check this hypothesis, methyl methacrylate (MMA) was polymerized as model monomer in the presence of GA (1 eq.) through a thermally initiated free radical polymerization at $70^{\circ} \mathrm{C}$ using $\mathrm{AIBN}$ as initiator (data not shown). As predicted, polymerization of MMA was very slow due to the retardation effect of 
phenolic hydroxyl groups of GA. Therefore, protection of the 3 hydroxyl functions of GA is required to reach high monomer conversion of the GA-based monomers. For this aim, on the one hand, benzyl protector group was selected given its very common use for this protection. On the other hand, two polymerizable model functions (acrylate and methacrylate) were linked to the protected GA.

Perbenzylated acrylate (BnGA-A) and perbenzylated methacrylate (BnGA-MA) monomers were prepared in two steps (Scheme 1). Firstly, 3,4,5-tribenzyloxybenzoic acid (3) was prepared then esterified with 2-hydroxyethyl(meth)acrylate in the presence of EDC.HCl and DMAP to prepare new protected GA-based acrylate and (meth)acrylates (BnGA-A and BnGA-MA). ${ }^{1} \mathrm{H}$ NMR spectra of BnGA-A and BnGA-MA (Figure 2) displayed multiplets between 4.30 and 4.60 ppm that correspond to the four protons between the two ester functions. Ethylenic protons are observed between 5.60 to $6.45 \mathrm{ppm}$, when the chemical shift of the methyl protons of BnGA-MA is $1.87 \mathrm{ppm}$. Aromatic protons are observed from 7.00 to $7.60 \mathrm{ppm}$, when benzylic protons displayed two peaks at 5.05 and $5.16 \mathrm{ppm}$. Integration of all these various peaks confirmed the good functionalization of BnGA-A and BnGA-MA.

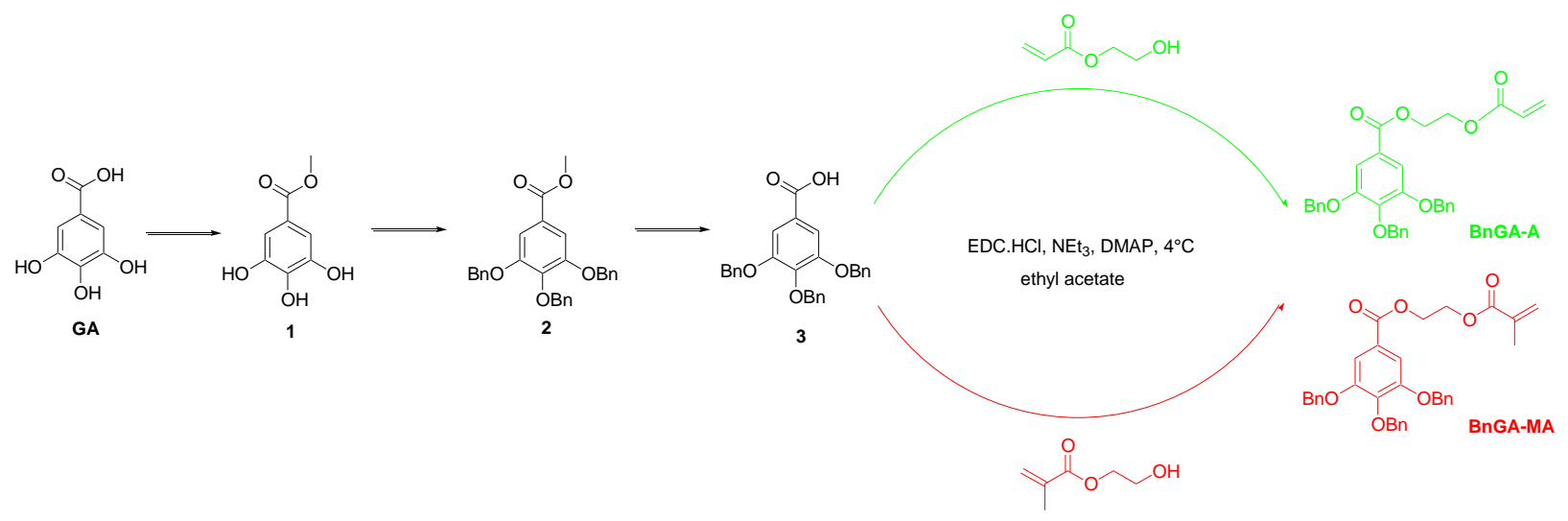

Scheme 1. Synthesis of perbenzylated GA-based monomers. 


\section{Polymerization of perbenzylated GA-based monomers}

On the first hand, the free radical homopolymerization of BnGA-A and BnGA-MA was carried out in DMSO at $70^{\circ} \mathrm{C}$ using AIBN to check the polymerizability of these novel perbenzylated monomers. Aliquots of the reaction mixture were withdrawn to follow the polymerization kinetics by ${ }^{1} \mathrm{H}$ NMR. As shown in Figure S4, the ${ }^{1} \mathrm{H}$ NMR spectrum of the crude medium of the polymerization of BnGA-MA within 2 hours confirms the decrease of the ethylenic protons peaks with respect to that of aromatic ones during the polymerization. The plot of the monomer conversion ( $\mathrm{x}$ ) vs time (Figure 3A) shows different rates of polymerization. High conversion (96\%) was achieved within 22 hours for BnGA-MA when lower conversion was observed for BnGA-A indicating the presence of radical deactivation reactions. However, whichever the monomer was, the evolution of the first-order kinetic plots $v s$ time (Figure 3B) was not linear in agreement with an uncontrolled free radical polymerization. After 22 hours of polymerization, SEC traces of polymers derived from BnGA-A and BnGA-MA (P(BnGA-A) and P(BnGA-MA), respectively) are given in Figure S5 and the molecular weight distributions are resumed in Table 1 .
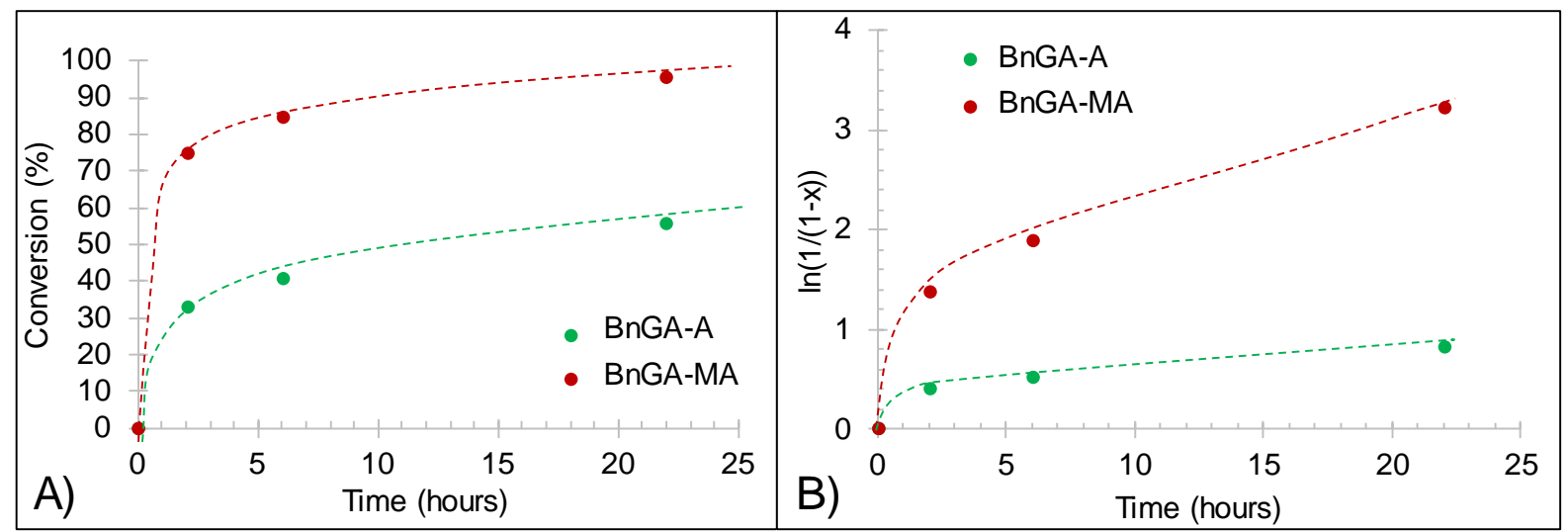
Figure 3. Monomer conversion (A) and semilogarithmic (B) plots vs time during the polymerization of BnGA-A and BnGA-MA initiated by $\mathrm{AIBN}$ in DMSO at $70^{\circ} \mathrm{C}$.

Table 1. Free radical polymerization and photo-RAFT polymerizations in DMSO $(1 \mathrm{~mol} / \mathrm{mL})$ of BnGA-A and BnGA-MA.

\begin{tabular}{|c|c|c|c|c|c|}
\hline Monomer & System & Conversion $(\%)^{\mathrm{c}}$ & $\overline{\mathrm{M}}_{\mathrm{n}_{\mathrm{NMR}}}(\mathrm{kg} / \mathrm{mol})^{\mathrm{d}}$ & $\overline{\mathrm{M}}_{\mathrm{nSEC}}(\mathrm{kg} / \mathrm{mol})^{\mathrm{e}}$ & $\mathrm{D}^{\mathrm{e}}$ \\
\hline \multirow{3}{*}{ BnGA-A } & $\mathrm{AIBN}^{\mathrm{a}}$ & 56 & 60.28 & 34.70 & 1.31 \\
\hline & $\mathrm{CTA}^{\mathrm{b}}$ & 46 & 49.79 & 49.00 & 1.15 \\
\hline & $\mathrm{CTA} 2^{\mathrm{b}}$ & 55 & 59.44 & 38.90 & 1.13 \\
\hline \multirow{3}{*}{ BnGA-MA } & $\mathrm{AIBN}^{\mathrm{a}}$ & 96 & 106.10 & 210.00 & 1.57 \\
\hline & $\mathrm{CTA}^{\mathrm{b}}$ & 89 & 98.64 & 93.00 & 1.26 \\
\hline & CTA $2^{\mathrm{b}}$ & 90 & 99.70 & 68.46 & 1.24 \\
\hline
\end{tabular}

a) $[\mathrm{M}]_{0} /[\mathrm{AIBN}]_{0}=200 / 1$ at $70^{\circ} \mathrm{C}$ during 22 hours.

b) $[\mathrm{M}]_{0} /[\mathrm{CTA}]_{0} /[\mathrm{TPO}-\mathrm{L}]=200 / 1 / 0.33$ at $405 \mathrm{~nm}$ irradiation during $2 \mathrm{~h}$ at $\mathrm{RT}$.

c) Conversion determined by ${ }^{1} \mathrm{H}$ NMR according to equations given in Table $\mathrm{S} 1$.

d) $\bar{M}_{n_{N M R}}=$ conversion $\times M_{0} \times 200+M_{C T A}$, with $M_{0}$ the respective molecular weight of

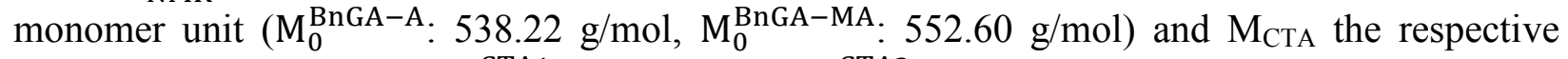
molecular weight of CTA $\left(\mathrm{M}_{0}^{\text {CTA1 }}: 277.43 \mathrm{~g} / \mathrm{mol}, \mathrm{M}_{0}^{\mathrm{CTA} 2}: 238.03 \mathrm{~g} / \mathrm{mol}\right)$.

e) Experimental number average molar mass and dispersity estimated by SEC analysis in THF at $40^{\circ} \mathrm{C}$.

On the other hand, photo-RAFT of both monomers was investigated in DMSO at RT (Scheme 2) as this technique was proven to be an effective route for the polymerization of (meth)acrylic monomers as we already reported. ${ }^{50-52,56,60-61}$ Accordingly, in the present study, the photo-RAFT of BnGA-A and BnGA-MA were carried out using initial molar ratios $[\mathrm{CTA}]_{0} /[\mathrm{TPO}-\mathrm{L}]_{0}=3$ and 
$[\mathrm{M}]_{0} /[\mathrm{CTA}]_{0}=200$, and the visible light $(405 \mathrm{~nm})$ was used to activate decomposition of TPO-L

(Figure S6) and to prevent CTAs from photolysis reaction. ${ }^{52,61}$

Table 1 summarizes the conversion, the molar masses and dispersity obtained for each case. ${ }^{1} \mathrm{H}$ NMR spectra of $\mathrm{P}(\mathrm{BnGA}-\mathrm{A})$ and $\mathrm{P}(\mathrm{BnGA}-\mathrm{MA})$ are shown in Figures 4 and $\mathrm{S} 7$. In case of BnGA-MA monomer, the ${ }^{1} \mathrm{H}$ NMR spectrum of pure $\mathrm{P}(\mathrm{BnGA}-\mathrm{MA})$ shows the complete disappearance of vinylic hydrogens at 5.69 at $6.05 \mathrm{ppm}$ (Figure 4). Moreover, the chemical shifts of benzylic protons ( $\mathrm{i}, \mathrm{g}$ and $\mathrm{h}$ ), as well as those of protons $\mathrm{d}$ and $\mathrm{e}$, have shifted to lower ppm upon polymerization with the appearance of new aliphatic main-chain protons below 2 ppm. ${ }^{13} \mathrm{C}$ NMR spectra of these compounds are drawn in Figure S8 and support again the disappearance of the $\mathrm{C}=\mathrm{C}$ bond of the monomers (shift of the ethylenic $\mathrm{C}$ peaks from 125-135 ppm range (Figure $\mathrm{S} 2$ ) to alkyl ones around $20 \mathrm{ppm}$ ). FTIR spectra confirm also the disappearance of vinylic $\mathrm{C}=\mathrm{C}$ band around $1635 \mathrm{~cm}^{-1}$ (Figure S3).
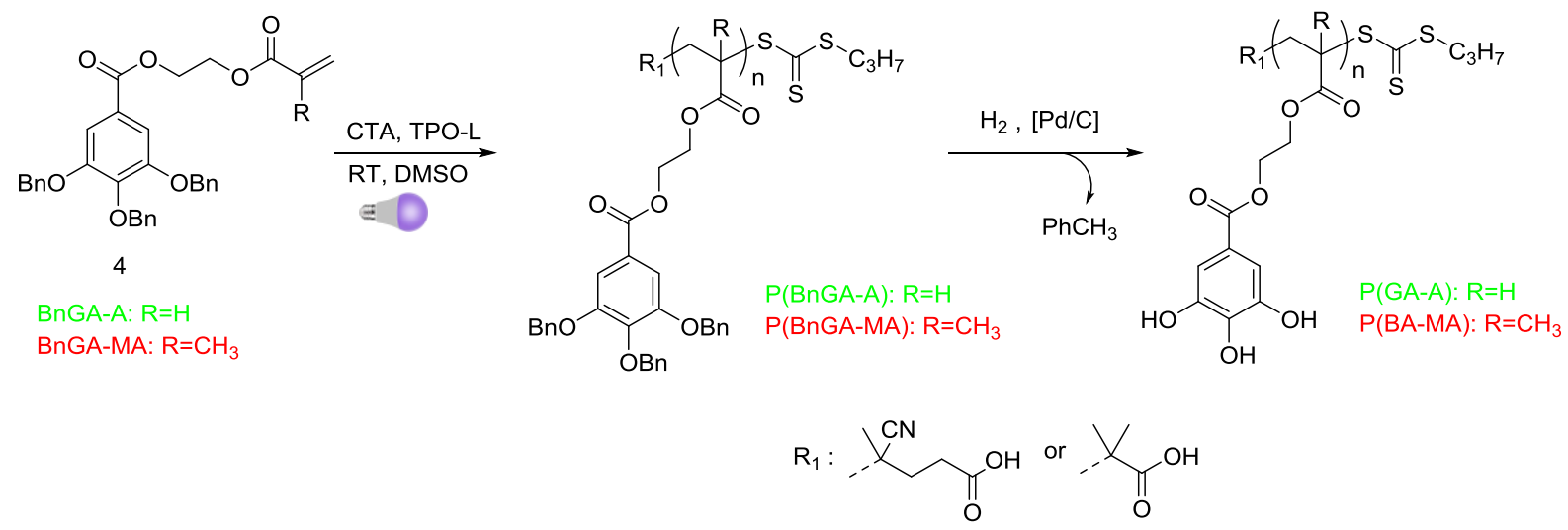

Scheme 2. Synthesis of free GA-based polymers through photo-RAFT of BnGA-A and BnGAMA.

We firstly investigated the influence of the chain transfer agent in the presence of TPO-L as photoinitiator. The first-order kinetic plots $v s$ time of polymerization performed with CTA1 or 
CTA2 are shown in Figures 5A and 5B. Whichever the CTA used, uncontrolled polymerizations of BnGA-A occur reaching moderate conversion rates (46-55\%) after 2 hours of irradiation. Such conversions are very similar to those observed using AIBN to initiate the free radical polymerization (Figure 3B). Surprisingly, the polymerizations of BnGA-A were not as efficient as expected although CTA2 is known to be more compatible with acrylates than methacrylates. However, by comparing the SEC traces of $\mathrm{P}(\mathrm{BnGA}-\mathrm{A})$ obtained from polymerization using these two CTAs after 2 hours, one can observe a pic referring to dead chains of high molar masses in the case of CTA1 (Figure S9) and not with CTA2. Note that the amount of such dead chains (with CTA1) is very limited in comparison to the free thermal polymerization in the presence of AIBN (Figure S5). Such dead chains can be explained by a lower reactivity of this acrylate-based monomer inducing some limited free radical polymerization at early stage of polymerization before the establishment of the main RAFT equilibrium.

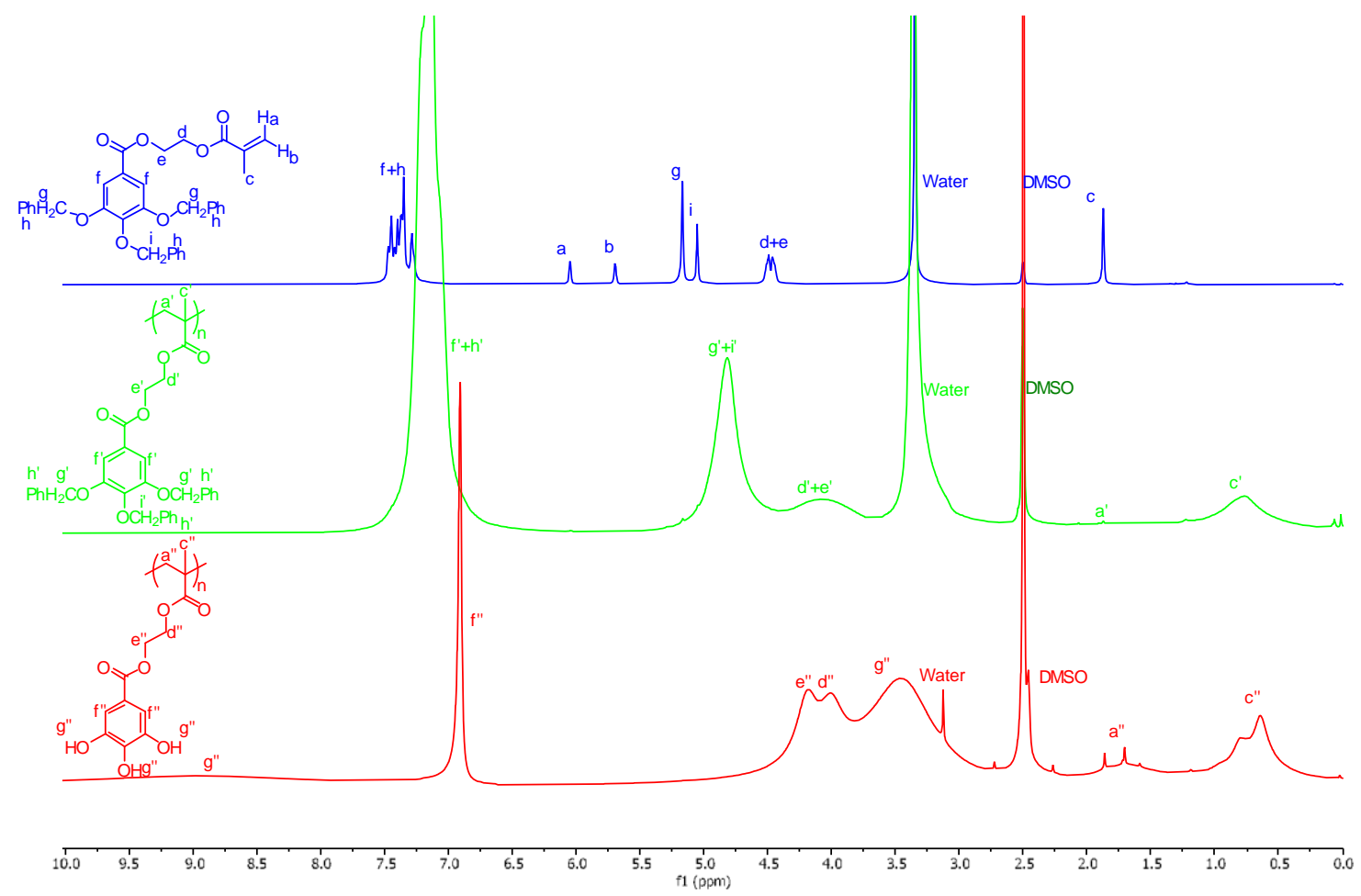


Figure 4. ${ }^{1} \mathrm{H}$ NMR spectra (DMSO- $\left.d_{6}\right)$ of BnGA-MA (Blue), P(BnGA-MA) (Green) and P(GA-MA) (Red).

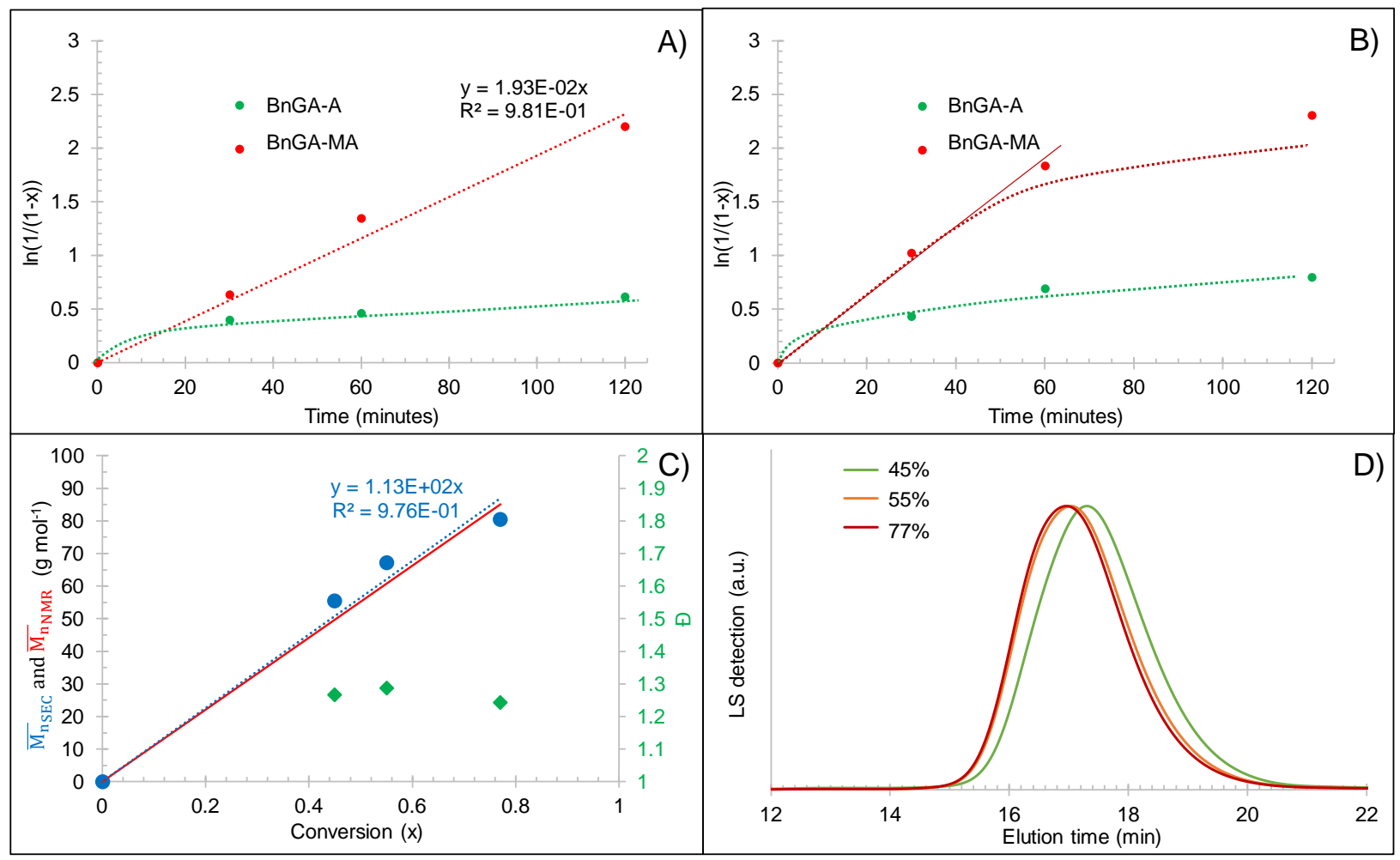

Figure 5. Semilogarithmic plots $v s$ polymerization time during the photo-RAFT using CTA1 (A) or CTA2 (B) as chain transfer agent. $[\mathrm{M}]_{0} /[\mathrm{CTA}]_{0} /[\mathrm{TPO}-\mathrm{L}]_{0}=200 / 1 / 0.33$, DMSO, RT, $405 \mathrm{~nm}$. (C) Plots of $\overline{\mathrm{M}}_{\mathrm{n}}, \overline{\mathrm{M}}_{\mathrm{n}_{\mathrm{NMR}}}$ and $Đ v s$ conversion and (D) SEC traces evolution (LS detection) in the case of photo-RAFT polymerization of BnGA-MA carried out with CTA1.

As shown in Table 1, almost $90 \%$ of BnGA-MA conversion was reached after 2 hours of polymerization whichever the CTA used. A linear first-order kinetic is observed until $89 \%$ of monomer conversion (2 hours of polymerization, Figure 5A) with CTA1, whereas the linearity was lost after 1 hour in the presence of CTA2 (84\% of conversion, Figure 5B). SEC analysis 
after 2 hours of polymerization confirm this lost control with CTA2 as ${\overline{\mathrm{M}_{\mathrm{n}}}}_{\mathrm{SEC}}$ and $\overline{\mathrm{M}}_{\mathrm{n}_{\mathrm{NMR}}}$ are not in agreement in such a case (Table 1). However, our results are suggesting that both CTA are efficient to control the photo-RAFT of BnGA-MA. Example of the evolution of the molecular weight and dispersity vs monomer conversion are shown in Figures 5C and 5D (PBnGA-MA prepared in the presence of CTA1). Consistent experimental molecular weights estimated by both ${ }^{1} \mathrm{H}$ NMR and SEC $\left({\overline{\mathrm{M}_{\mathrm{n}}}}_{\mathrm{NMR}}\right.$ and $\left.\overline{\mathrm{M}}_{\mathrm{n}_{\mathrm{SEC}}}\right)$ were recorded throughout the conversion range. The low dispersities $(Ð=1.3)$ and the shift of chromatograms toward low elution time recorded at different conversion demonstrate the control of the photo-RAFT of BnGA-MA when using CTA1/TPO-L system. Finally, we investigated the chain-end fidelity within this system. BnGAMA was polymerized using CTA1 and TPO-L up to 50\% conversion. The polymer was then purified $\left(\overline{\mathrm{M}}_{\mathrm{nEC}}=52700 \mathrm{gmol}^{-1}, \mathrm{D}=1.18\right)$ and used as a macro-CTA to initiate a new polymerization of BnGA-MA. The polymerization proceeded with $20 \%$ conversion. SEC analysis of the final polymer $\left(\overline{\mathrm{M}}_{\mathrm{nEC}}=83600 \mathrm{gmol}^{-1}, \mathrm{Đ}=1.27\right.$, Figure 6$)$ showed a shifted trace toward lower elution time without a significant increase of the dispersity, supporting the high efficiency of such controlled photo-RAFT of BnGA-MA.

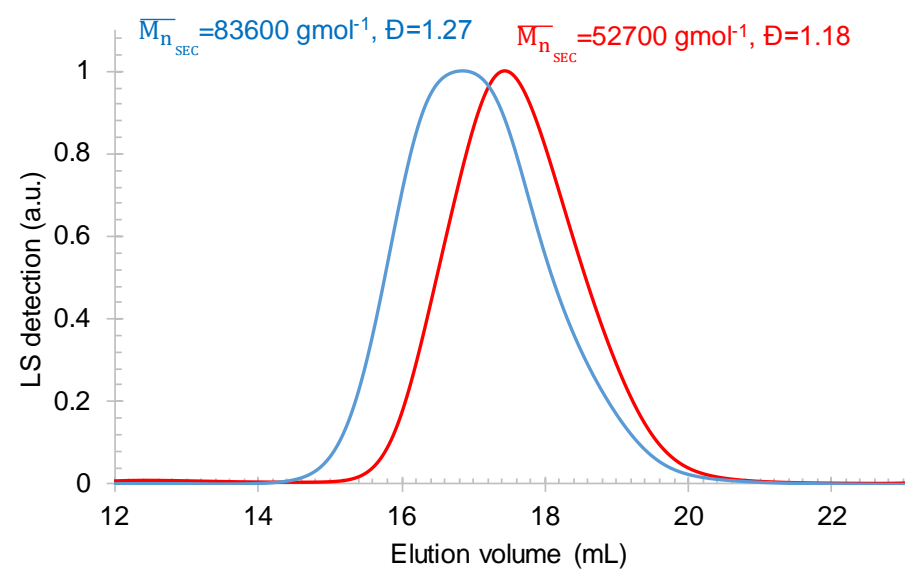


Figure 6. Evolution of SEC traces (LS detection) after a sequential polymerization of BnGAMA. $[\mathrm{M}]_{0} /[\mathrm{CTA} 1]_{0} /[\mathrm{TPO}-\mathrm{L}]_{0}=200 / 1 / 0.33, \mathrm{DMSO}, \mathrm{RT}, 405 \mathrm{~nm}$.

\section{Free GA-based polymers}

In the following step, free GA-based polymers (P(GA-A) and $\mathrm{P}(\mathrm{GA}-\mathrm{MA}))$ were obtained after the deprotection of previous perbenzylated $\mathrm{P}(\mathrm{BnGA}-\mathrm{A})$ and $\mathrm{P}(\mathrm{BnGA}-\mathrm{MA})$ that were produced after 2 hours by photo-RAFT. Heterogenous Pd/C catalysis was used under relatively mild conditions $\left(\mathrm{H}_{2}\right.$ pressure $=25$ bars, $\left.\mathrm{RT}, 48 \mathrm{~h}\right)$ to deprotect each repeating unit of the protected polymers (Scheme 2). The free GA-based polymers were recovered by dialysis purification in methanol (limited options of dialysis solvent due to the polymer solubility) as light-greyish white to light-yellowish white solids (60\% yields). To support the appearance of the free GA moiety per monomer unit on the different polymers, ${ }^{1} \mathrm{H}$ and ${ }^{13} \mathrm{C}$ NMR spectra were registered. Figures 4 and S7 demonstrate the total disappearance of the benzyl protecting groups (peaks g', h' and i') and the shift of the aromatic peak (f") to $6.8 \mathrm{ppm}$ which is consistent with the aromatic protons of free GA (Figure S1). The total disappearance of the protecting groups was also evidenced by the ${ }^{13} \mathrm{C}$ NMR spectra (from 125 to $140 \mathrm{ppm}$ ) after the hydrogenolysis (Figures S8 vs S10) when the aromatic C (peaks 9 and 10) shifted to lower ppm, in accordance with the ${ }^{13} \mathrm{C}$ NMR of gallic acid. As shown in Figure S3, FTIR analyses of P(GA-A) and P(GA-MA) showed the appearance of bands around $3250 \mathrm{~cm}^{-1}$ corresponding to O-H stretch absorption. SEC traces of free GAbased polymers are reported in Figure 7. SEC analysis was done in $\mathrm{DMSO} / \mathrm{NaNO}_{3}$ due to the lack of solubility of free GA-based polymers in THF. After hydrogenolysis of benzyl protecting groups, an increase of the dispersity values has been registered (Table 2) in agreement with both the establishment of many hydrogen bonds between the numerous phenolic functions of the 
polymeric chains and the possible adhesion of the chains onto the column. The difference between ${\overline{\mathrm{M}_{\mathrm{n}}}}_{\mathrm{NMR}}$ and experimental $\overline{\mathrm{M}}_{\mathrm{n}}$ values was related to the use of PMMA calibration.

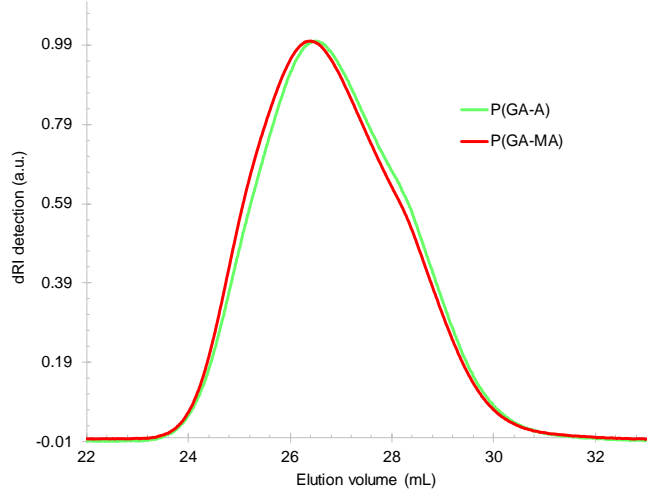

Figure 7. SEC traces (LS detection) of $\mathrm{P}(\mathrm{GA}-\mathrm{A})$ and $\mathrm{P}(\mathrm{GA}-\mathrm{MA})$.

Table 2. Molecular and thermal characterization of polymers before and after deprotection.

\begin{tabular}{|c|c|c|c|c|}
\hline \multicolumn{5}{|c|}{ Perbenzylated polymers } \\
\hline Polymer $^{\mathrm{a}}$ & ${\overline{\mathrm{M}_{\mathrm{n}}}}_{\mathrm{NR}}(\mathrm{kg} / \mathrm{mol})^{\mathrm{b}}$ & $\overline{\overline{\mathrm{M}}}_{\mathrm{SEC}}(\mathrm{kg} / \mathrm{mol})^{\mathrm{c}}$ & $\oplus^{\mathrm{c}}$ & $\mathrm{T}_{\mathrm{g}}\left({ }^{0} \mathrm{C}\right)^{\mathrm{d}}$ \\
\hline $\mathrm{P}(\mathrm{BnGA}-\mathrm{A})$ & 59.44 & 38.90 & 1.24 & 35.8 \\
\hline P(BnGA-MA) & 98.64 & 93.00 & 1.26 & 28.1 \\
\hline \multicolumn{5}{|c|}{ Free GA-based polymers } \\
\hline Polymer & ${\overline{\mathrm{M}_{\mathrm{n}}}}_{\mathrm{NMR}}(\mathrm{kg} / \mathrm{mol})^{\mathrm{e}}$ & ${\overline{\mathrm{M}_{\mathrm{n}}}}_{\mathrm{SEC}}(\mathrm{kg} / \mathrm{mol})^{\mathrm{f}}$ & $\nexists^{\mathrm{f}}$ & $\mathrm{T}_{\mathrm{g}}\left({ }^{0} \mathrm{C}\right)^{\mathrm{d}}$ \\
\hline $\mathrm{P}(\mathrm{GA}-\mathrm{A})$ & 29.74 & 184.70 & 1.56 & 129.5 \\
\hline $\mathrm{P}(\mathrm{GA}-\mathrm{MA})$ & 50.58 & 296.20 & 1.51 & 127.2 \\
\hline
\end{tabular}

a) $\mathrm{P}(\mathrm{BnGA}-\mathrm{A})(\mathrm{P}(\mathrm{BnGA}-\mathrm{MA}))$ were obtained by photo-RAFT after 2 hours of irradiation (see Table 1).

b) $\bar{M}_{n_{N M R}}=$ conversion $\times M_{0} \times 200+M_{\text {CTA }}$, with $M_{0}$ the respective molecular weight of

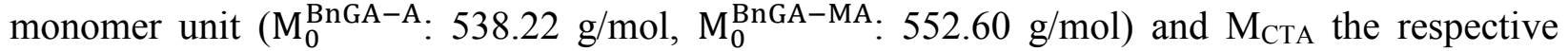
molecular weight of CTA ( $\left.\mathrm{M}_{0}^{\text {CTA1 }}: 277.43 \mathrm{~g} / \mathrm{mol}, \mathrm{M}_{0}^{\text {CTA2 }}: 238 \mathrm{~g} / \mathrm{mol}\right)$.

c) Experimental number average molar mass and dispersity estimated by SEC analysis in THF at $40^{\circ} \mathrm{C}$. 
d) Glass transition temperature measured using the $2^{\text {nd }}$ heating cycle.

e) $\bar{M}_{\mathrm{n}_{\mathrm{NMR}}}=$ conversion $\times \mathrm{M}^{\prime}{ }_{0} \times 200+\mathrm{M}_{\mathrm{CTA}}$, with $\mathrm{M}^{\prime}$ o the respective molecular weight of deprotected monomer unit $\left(\mathrm{M}_{0}^{\mathrm{GA}-\mathrm{A}}: 268.22 \mathrm{~g} / \mathrm{mol}, \mathrm{M}_{0}^{\mathrm{GA}-\mathrm{MA}}: 282.60 \mathrm{~g} / \mathrm{mol}\right)$

f) Experimental number average molar mass and dispersity estimated by SEC analysis in $\mathrm{DMSO} / \mathrm{NaNO}_{3}$ at $70^{\circ} \mathrm{C}$. (SEC traces in Figure 7).

\section{Thermal characteristics of perbenzylated-GA and free GA based polymers}

The thermal characteristics of the perbenzylated polymers and their corresponding free GAbased polymers were determined by DSC and TGA (Table 2). As expected, $\mathrm{P}(\mathrm{BnGA}-\mathrm{A})$ shows a higher Tg value than the polymethacrylate $\mathrm{P}(\mathrm{BnGa}-\mathrm{MA})\left(35.8^{\circ} \mathrm{C} v s 28.1^{\circ} \mathrm{C}\right)$. After deprotection, Tg increased by almost $100^{\circ} \mathrm{C}$ to reach $129.5^{\circ} \mathrm{C}$ in case of $\mathrm{P}(\mathrm{GA}-\mathrm{A})$ and $127.2^{\circ} \mathrm{C}$ in case of $\mathrm{P}(\mathrm{GA}-\mathrm{MA})$, due to the establishment of many hydrogen bonds between the numerous phenolic functions of the polymeric chains and the significant decrease in the steric hindrance around the polymer backbone. Thermo-gravimetric analysis (TGA) revealed a similar behaviour for the two perbenzylated polymers with an initial loss of mass upon heating at about $250^{\circ} \mathrm{C}$ (Table 2 , Figure S11). Such protected polymers showed higher thermal stability than the deprotected ones bearing free GA moieties as $\mathrm{P}(\mathrm{GA}-\mathrm{A})$ and $\mathrm{P}(\mathrm{GA}-\mathrm{MA})$ gradually degraded when the temperature was over $\mathrm{Tg}$ for $\mathrm{P}(\mathrm{GA}-\mathrm{A})\left(170^{\circ} \mathrm{C}\right.$ for $\left.\mathrm{P}(\mathrm{GA}-\mathrm{MA})\right)$. TGA of free GA-based polymers presented one three-step thermal degradation behavior. All the studied polymers exhibited a final weight percentage loss around $80 \%$. Currently, we have no explanation to explain these results. Supplementary experiments will be planned in the near future to investigate the degradation mechanism of such novel $\mathrm{P}(\mathrm{GA}-\mathrm{A})$ and $\mathrm{P}(\mathrm{GA}-\mathrm{MA})$ polymers.

\section{Antioxidant activity of free GA-based polymers}


As GA is one of the best natural antioxidants, we expect that polymers carrying free GA moiety in each monomer unit ( $\mathrm{P}(\mathrm{GA}-\mathrm{A})$ and $\mathrm{P}(\mathrm{GA}-\mathrm{MA}))$ exhibit such property. To demonstrate that, we first carried out DPPH radical scavenging assays with deprotected polymers or with GA as model. The antioxidant activity of GA and of the free-GA based polymers turned down the DPPH absorbance, and was easily observed as the colour of the solution changed instantly from purple (DPPH) to yellow upon DPPH disappearance according to Scheme 3 leading to very stable radical forms of GA. ${ }^{59}$ As the concentration of GA or GA-based monomer unit increased, the absorption of DPPH of the mixture at $517 \mathrm{~nm}$ (absorption maximum wavelength) dropped gradually to reach a plateau after 12 minutes of reaction. On the contrary, the color of the DPPH solution didn't change when adding perbenzylated polymers (not shown). While protected polymers showed no signs of an antioxidant activity, all free GA-based polymers actively exhibit excellent antioxidant activity.

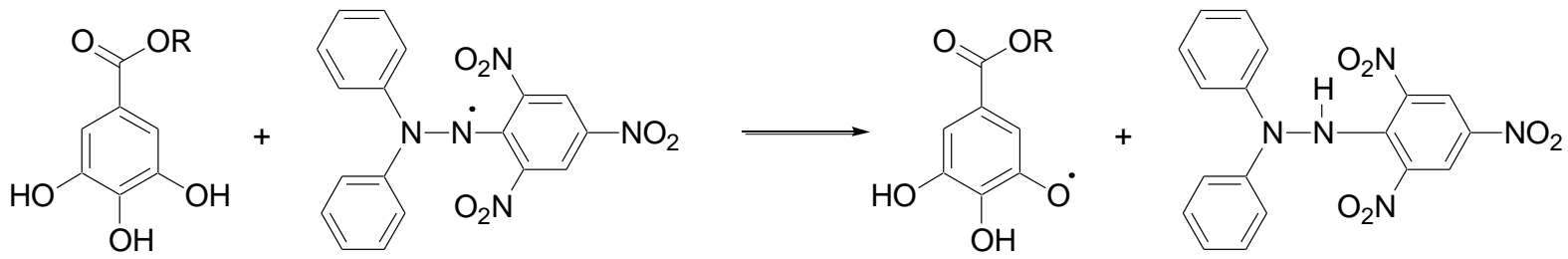

$$
\text { GA or }
$$

GA-based monomer unit

DPPH

Scheme 3. Reaction between DPPH and GA or GA-based monomer unit.

The absorption decreases with respect to the concentration of the tested antioxidants and the percentage of reduced $\mathrm{DPPH}$ are represented in figures $8 \mathrm{~A}$ and $8 \mathrm{~B}$, respectively. $\mathrm{P}(\mathrm{GA}-\mathrm{A})$ and P(GA-MA) generated likewise DPPH radicals scavenging behaviour whereas lower concentrations of GA were administrated to achieve similar DPPH mixture absorptions (Figure 
$8 \mathrm{~A})$. This is demonstrated by the values of the critical concentration $\left(\mathrm{C}_{50}\right)$ at which $50 \%$ of the initial DPPH radicals are reduced. As shown in Figure 8B, the percentage of scavenged DPPH radicals was proportional to the concentrations of GA or GA repeating units up to high degrees of reduction in a linear mode. With our experimental conditions, $\mathrm{C}_{50}$ of GA was registered at about $8 \mu \mathrm{M}$. The free GA-based polymers produced in the present study showed higher $\mathrm{C}_{50}$ values at about $13.5 \mu \mathrm{M}$ and $14.5 \mu \mathrm{M}$ of GA-based monomer units for P(GA-A) and P(GA-MA), respectively. Nevertheless, $\mathrm{P}(\mathrm{GA}-\mathrm{A})$ and $\mathrm{P}(\mathrm{GA}-\mathrm{MA})$ demonstrated a marginally better antioxidant activity than the previously reported polyvinylgallol $\left(\mathrm{C}_{50}=32 \mu \mathrm{M}\right.$ of gallol-based monomer units) and similar activity to gallol $\left(\mathrm{C}_{50}=16.3 \mu \mathrm{M}\right) .{ }^{44}$ Such advantage can be accredited to the spacer between each polyphenol group and the chain backbone in $\mathrm{P}(\mathrm{GA}-\mathrm{A})$ and P(GA-MA) granting a higher mobility of such a group compared to gallol one in the previously reported polyvinylgallol. The lower antioxidant properties of free GA-based polymers vs GA was attributed to the lower accessibility of adjacent GA monomer units due to the steric hindrance from the polymeric chains, in agreement with litterature. ${ }^{44}$

Another method to evaluate the antioxidant activity of free GA-based polymers is to study the oxygen uptake inhibition during the oxidation of methyl linoleate initiated by AIBN. ${ }^{62}$ Usually, methyl linoleate can undergo oxidation in the presence of radicals and oxygen (Figure S12) but this oxidation may be inhibited in the presence of an antioxidant. Initially, the oxidation of methyl linoleate was studied through the monitoring of the evolution of the pressure of $\mathrm{O}_{2}(\Delta \mathrm{P}=$ $\mathrm{P}_{0}\left(\mathrm{O}_{2}\right)-\mathrm{P}_{2.5 \text { hours }}\left(\mathrm{O}_{2}\right)$ ) in the reactor (Figure $8 \mathrm{C}$ ). The oxygen uptake inhibition index (OUI, Figure 8D) was plotted according to equation 2. Assays were performed in the presence of GA as model, $\mathrm{P}(\mathrm{GA}-\mathrm{A})$ and $\mathrm{P}(\mathrm{GA}-\mathrm{MA})$ using the same molar concentration of GA moiety. As shown, GA caused the inhibition percentage of $75 \%$ after 2.5 hours, whereas those of $\mathrm{P}(\mathrm{GA}-\mathrm{A})$ and 
$\mathrm{P}(\mathrm{GA}-\mathrm{MA})$ were similar at $55 \%$ at the same time. The difference of values between GA and free GA-based polymers can nevertheless be explained by the low solubility of the polymers in the reaction medium as 1-butanol is the common used solvent to carry out this experiment but does not dissolve $\mathrm{P}(\mathrm{GA}-\mathrm{A})$ and $\mathrm{P}(\mathrm{GA}-\mathrm{MA})$. In such a case, DMSO was consequently added in the medium to keep the polymers soluble, whereas GA is highly soluble in both solvents. Nevertheless, such results mirror the ones obtained from the study of the reduction of DPPH radicals and confirm the antioxidant property of (GA-A) and P(GA-MA).

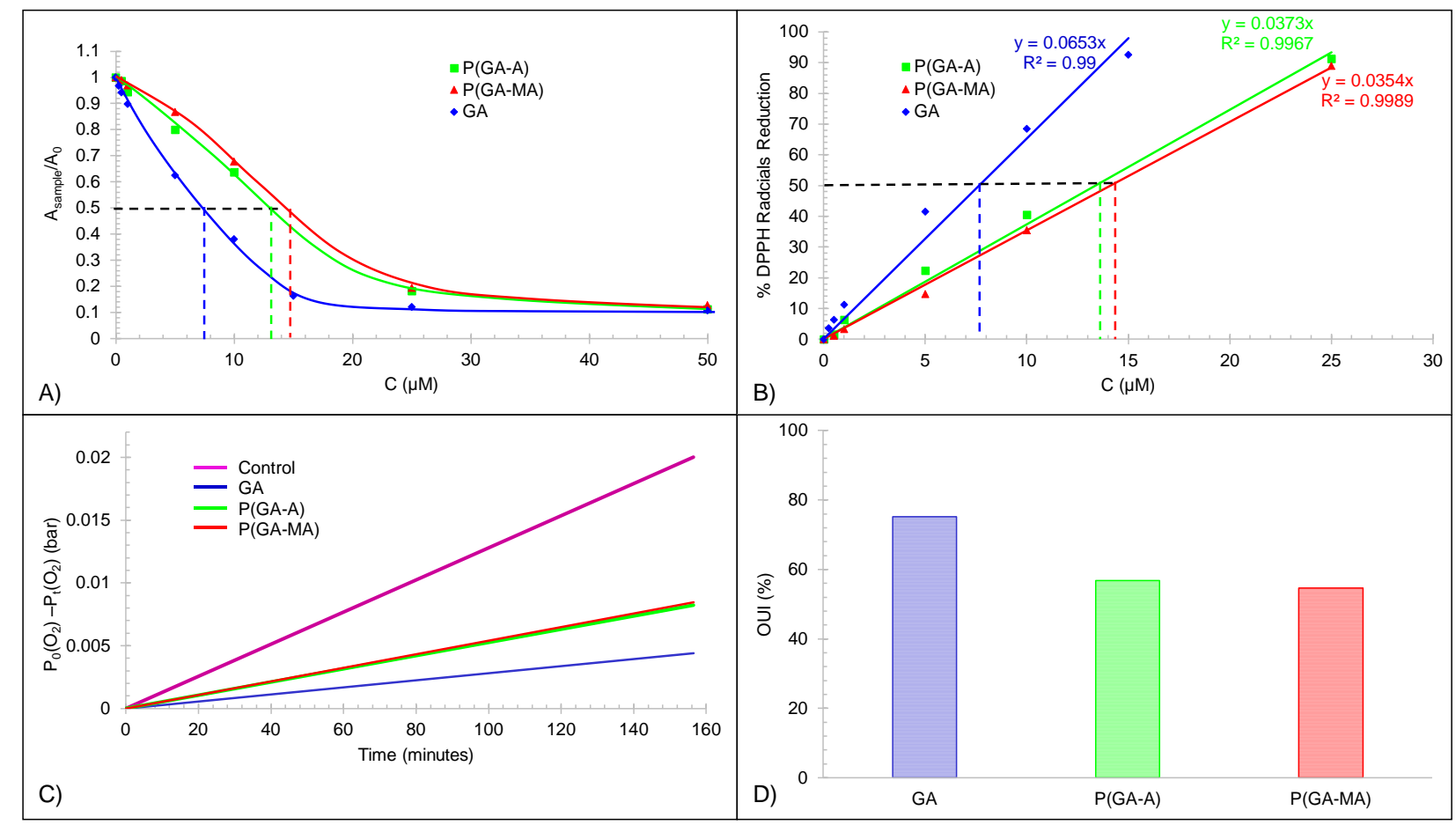

Figure 8. Antioxidant activity of GA and of free GA-based polymers (P(GA-A) and P(GA-MA). Evolutions of A) the relative absorbance values of the DPPH/antioxidant system in $\mathrm{MeOH}, \mathrm{B}$ ) the percentage of reduced DPPH radical $v s$ the concentration of the GA or GA-monomer units, C) the pressure difference $\left(\mathrm{P}_{0}\left(\mathrm{O}_{2}\right)-\mathrm{P}_{\mathrm{t}}\left(\mathrm{O}_{2}\right)\right)$ in the reactor containing methyl linoleate, AIBN and antioxidant and D) the antioxidant uptake inhibition index (OUI) of GA/GA-based polymers 


\section{CONCLUSION}

Novel GA-based acrylate and methacrylate were prepared according to a multistep strategy to further allow their radical polymerization. Photo-mediated RAFT polymerization was herein selected as a low-energy, spatio and temporal controlled technique where its efficiency was investigated depending on the monomer and the choice of CTA. Contrary to the acrylate one, perbenzylated GA-based methacrylate was proved to be polymerized in a controlled manner with an adequate choice of chain transfer agent. Later on, hydrogenolysis of these (meth)acrylic polymers under mild conditions readily resulted in free GA-based polymers.

The antioxidant efficiency of these free GA-based polymers was studied in comparison with that of gallic acid, showing a very efficient scavenging of DPPH radicals. Similarly, the inhibition of methyl linoleate oxidation by free GA-based polymers was proven and compared to that of GA. In accordance with these properties and their thermal characteristics, such free GAbased polymers can be used as bioactive thermoplastic packaging in food industry for instance. Moreover, we believe that these antioxidant bio-based polymers will also be of interest for various applications in cosmetics or in pharmaceutical domain for instance.

\section{ASSOCIATED CONTENT}

Supporting Information. ${ }^{1} \mathrm{H}$ NMR and J-mod ${ }^{13} \mathrm{C}$ NMR spectra. ATR-FTIR spectra. Equations used to estimate the conversion. SEC traces. Photo-induced decomposition of TPO-L, then initiation of the polymerization. TGA thermograms. Oxidation of methyl linoleate. 


\section{AUTHOR INFORMATION}

\section{Corresponding Author}

Correspondance to Jean-Luc Six (E-mail: jean-luc.six @univ-lorraine.fr) and Christine GérardinCharbonnier (E-mail: christine.gerardin@univ-lorraine.fr).

\section{Author Contributions}

The manuscript was written through contributions of all authors. All authors have given approval to the final version of the manuscript.

\section{ACKNOWLEDGMENT}

The authors thank i) the "Impact Biomolecules" project of the "Lorraine Université d'Excellence', (Investissements d'avenir -ANR-15-IDEX-04-LUE) fund and ii) the Energy Mechanics Processes Products research department of the Université de Lorraine for the financial support. The authors thank Olivier Fabre (LCPM) for NMR characterization, Alexandre Collar (LCPM) for SEC characterization, Jean-Claude Sivault (LCPM) for homemade UV-VIS LED lamp development, and Béatrice Georges (LERMAB) for the antioxidant tests.

\section{REFERENCES}

1. Newman, D. J.; Cragg, G. M., Natural Products as Sources of New Drugs over the Nearly Four Decades from 01/1981 to 09/2019. Journal of Natural Products 2020, 83 (3), 770-803.

2. Lautié, E.; Russo, O.; Ducrot, P.; Boutin, J. A., Unraveling Plant Natural Chemical Diversity for Drug Discovery Purposes. Frontiers in pharmacology 2020, 11, 397-397.

3. Wright, G. D., Opportunities for natural products in 21 st century antibiotic discovery. Natural Product Reports 2017, 34 (7), 694-701.

4. Gonçalves, J.; Ramos, R.; Luís, Â.; Rocha, S.; Rosado, T.; Gallardo, E.; Duarte, A. P., Assessment of the Bioaccessibility and Bioavailability of the Phenolic Compounds of Prunus avium L. by in Vitro Digestion and Cell Model. ACS Omega 2019, 4 (4), 7605-7613. 
5. Tsimogiannis, D.; Oreopoulou, V., Chapter 16 - Classification of Phenolic Compounds in Plants. In Polyphenols in Plants (Second Edition), Watson, R. R., Ed. Academic Press: 2019; pp 263-284.

6. $\quad$ Roy, M.; Datta, A., Fundamentals of Phytochemicals. In Cancer Genetics and Therapeutics: Focus on Phytochemicals, Springer Singapore: Singapore, 2019; pp 49-81.

7. Panzella, L., Natural Phenolic Compounds for Health, Food and Cosmetic Applications. Antioxidants 2020, 9 (5), Article ID 427.

8. Arroyo, B. J.; Santos, A. P.; de Almeida de Melo, E.; Campos, A.; Lins, L.; BoyanoOrozco, L. C., Chapter 8 - Bioactive Compounds and Their Potential Use as Ingredients for Food and Its Application in Food Packaging. In Bioactive Compounds, Campos, M. R. S., Ed. Woodhead Publishing: 2019; pp 143-156.

9. Kumar, N.; Gupta, S.; Chand Yadav, T.; Pruthi, V.; Kumar Varadwaj, P.; Goel, N., Extrapolation of phenolic compounds as multi-target agents against cancer and inflammation. Journal of Biomolecular Structure and Dynamics 2019, 37 (9), 2355-2369.

10. Mark, R.; Lyu, X.; Lee, J. J. L.; Parra-Saldívar, R.; Chen, W. N., Sustainable production of natural phenolics for functional food applications. Journal of Functional Foods 2019, 57, 233254.

11. Subramanian, A. P.; John, A. A.; Vellayappan, M. V.; Balaji, A.; Jaganathan, S. K.; Supriyanto, E.; Yusof, M., Gallic acid: prospects and molecular mechanisms of its anticancer activity. RSC Advances 2015, 5 (45), 35608-35621.

12. Dróżdż, P.; Pyrzynska, K., Extracts from pine and oak barks: phenolics, minerals and antioxidant potential. International Journal of Environmental Analytical Chemistry 2019, 1-9.

13. Zhang, B.; Cai, J.; Duan, C.-Q.; Reeves, M. J.; He, F., A Review of Polyphenolics in Oak Woods. International Journal of Molecular Sciences 2015, 16 (4), 6978-7014.

14. Uddin, S. J.; Afroz, M.; Zihad, S. M. N. K.; Rahman, M. S.; Akter, S.; Khan, I. N.; AlRabbi, S. M. S.; Rouf, R.; Islam, M. T.; Shilpi, J. A.; Nahar, L.; Tiralongo, E.; Sarker, S. D., A Systematic Review on Anti-diabetic and Cardioprotective Potential of Gallic Acid: A Widespread Dietary Phytoconstituent. Food Reviews International 2020, 1-20.

15. Shabani, S.; Rabiei, Z.; Amini-Khoei, H., Exploring the multifaceted neuroprotective actions of gallic acid: a review. International Journal of Food Properties 2020, 23 (1), 736-752.

16. Kahkeshani, N.; Farzaei, F.; Fotouhi, M.; Alavi, S. S.; Bahramsoltani, R.; Naseri, R.; Momtaz, S.; Abbasabadi, Z.; Rahimi, R.; Farzaei, M. H.; Bishayee, A., Pharmacological effects of gallic acid in health and diseases: A mechanistic review. Iranian journal of basic medical sciences 2019, 22 (3), 225-237.

17. Bhattacharyya, S.; Ahammed, S. M.; Saha, B. P.; Mukherjee, P. K., The Gallic AcidPhospholipid Complex Improved the Antioxidant Potential of Gallic Acid by Enhancing Its Bioavailability. AAPS PharmSciTech 2013, 14 (3), 1025-1033.

18. Goszcz, K.; Deakin, S. J.; Duthie, G. G.; Stewart, D.; Megson, I. L., Bioavailable Concentrations of Delphinidin and Its Metabolite, Gallic Acid, Induce Antioxidant Protection Associated with Increased Intracellular Glutathione in Cultured Endothelial Cells. Oxidative Medicine and Cellular Longevity 2017, Article ID 9260701.

19. Ferruzzi, M. G.; Lobo, J. K.; Janle, E. M.; Cooper, B.; Simon, J. E.; Wu, Q.-L.; Welch, C.; Ho, L.; Weaver, C.; Pasinetti, G. M., Bioavailability of Gallic Acid and Catechins from Grape Seed Polyphenol Extract is Improved by Repeated Dosing in Rats: Implications for Treatment in Alzheimer's Disease. Journal of Alzheimer's Disease 2009, 18, 113-124. 
20. Chuysinuan, P.; Chimnoi, N.; Techasakul, S.; Supaphol, P., Gallic Acid-Loaded Electrospun Poly(L-Lactic Acid) Fiber Mats and their Release Characteristic. 2009, 210 (10), 814-822.

21. Ghitescu, R.-E.; Popa, A.-M.; Popa, V. I.; Rossi, R. M.; Fortunato, G., Encapsulation of polyphenols into pHEMA e-spun fibers and determination of their antioxidant activities. International Journal of Pharmaceutics 2015, 494 (1), 278-287.

22. Aydogdu, A.; Sumnu, G.; Sahin, S., Fabrication of gallic acid loaded Hydroxypropyl methylcellulose nanofibers by electrospinning technique as active packaging material. Carbohydrate polymers 2019, 208, 241-250.

23. Chebil, A.; Léonard, M.; Six, J.-L.; Nouvel, C.; Durand, A., Nanoparticulate delivery systems for alkyl gallates: Influence of the elaboration process on particle characteristics, drug encapsulation and in-vitro release. Colloids and Surfaces B: Biointerfaces 2018, 162, 351-361. 24. Chebil, A.; Funfschilling, D.; Six, J.-L.; Nouvel, C.; Durand, A.; Léonard, M., Process conditions for preparing well-defined nano- and microparticles as delivery systems of alkyl gallates. Particuology 2019, 44, 105-116.

25. Thanyacharoen, T.; Chuysinuan, P.; Techasakul, S.; Nooeaid, P.; Ummartyotin, S., Development of a gallic acid-loaded chitosan and polyvinyl alcohol hydrogel composite: Release characteristics and antioxidant activity. International Journal of Biological Macromolecules 2018, 107, 363-370.

26. Li, J.; Kim, S. Y.; Chen, X.; Park, H. J., Calcium-alginate beads loaded with gallic acid: Preparation and characterization. LWT - Food Science and Technology 2016, 68, 667-673.

27. Behl, G.; Sharma, M.; Sikka, M.; Dahiya, S.; Chhikara, A.; Chopra, M., Gallic acid loaded disulfide cross-linked biocompatible polymeric nanogels as controlled release system: synthesis, characterization, and antioxidant activity. Journal of Biomaterials Science, Polymer Edition 2013, 24 (7), 865-881.

28. Pinho, E.; Henriques, M.; Soares, G., Cyclodextrin/cellulose hydrogel with gallic acid to prevent wound infection. Cellulose 2014, 21 (6), 4519-4530.

29. Aouf, C.; Nouailhas, H.; Fache, M.; Caillol, S.; Boutevin, B.; Fulcrand, H., Multifunctionalization of gallic acid. Synthesis of a novel bio-based epoxy resin. European Polymer Journal 2013, 49 (6), 1185-1195.

30. Ma, S.; Jiang, Y.; Liu, X.; Fan, L.; Zhu, J., Bio-based tetrafunctional crosslink agent from gallic acid and its enhanced soybean oil-based UV-cured coatings with high performance. $R S C$ Advances 2014, 4 (44), 23036-23042.

31. Shim, J.; Kim, L.; Kim, H. J.; Jeong, D.; Lee, J. H.; Lee, J.-C., All-solid-state lithium metal battery with solid polymer electrolytes based on polysiloxane crosslinked by modified natural gallic acid. Polymer 2017, 122, 222-231.

32. Tarzia, A.; Montanaro, J.; Casiello, M.; Annese, C.; Nacci, A.; Maffezzoli, A., Synthesis, Curing, and Properties of an Epoxy Resin Derived from Gallic Acid. BioResources 2017, 13 (1), 632-645.

33. Ren, L.; Ma, X.; Zhang, J.; Qiang, T., Preparation of gallic acid modified waterborne polyurethane made from bio-based polyol. Polymer 2020, 194, Article ID 122370.

34. Can, M.; Bulut, E.; Özacar, M., Synthesis and Characterization of Gallic Acid Resin and Its Interaction with Palladium(II), Rhodium(III) Chloro Complexes. Industrial \& Engineering Chemistry Research 2012, 51 (17), 6052-6063. 
35. Uemura, Y.; Shimasaki, T.; Teramoto, N.; Shibata, M., Thermal and mechanical properties of bio-based polymer networks by thiol-ene photopolymerizations of gallic acid and pyrogallol derivatives. Journal of Polymer Research 2016, 23 (10), Article ID 216.

36. Li, X.; Su, Y.; Chen, Q.; Lin, Y.; Tong, Y.; Li, Y., Synthesis and Characterization of Biodegradable Hyperbranched Poly(ester-amide)s Based on Natural Material.

Biomacromolecules 2005, 6 (6), 3181-3188.

37. Reina, A.; Gerken, A.; Zemann, U.; Kricheldorf, H. R., New polymer syntheses, 101. Liquid-crystalline hyperbranched and potentially biodegradable polyesters based on phloretic acid and gallic acid. Macromol. Chem. Phys. 1999, 200 (7), 1784-1791.

38. Kricheldorf, H. R.; Stukenbrock, T., New polymer syntheses XCIII. Hyperbranched homo- and copolyesters derived from gallic acid and $\beta$-(4-hydroxyphenyl)-propionic acid.

Journal of Polymer Science: Part A: Polymer Chemistry 1998, 36 (13), 2347-2357.

39. Liu, J.; Yong, H.; Liu, Y.; Bai, R., Recent advances in the preparation, structural characteristics, biological properties and applications of gallic acid grafted polysaccharides. International Journal of Biological Macromolecules 2020, 156, 1539-1555.

40. Yan, M.; Li, B.; Zhao, X.; Yi, J., Physicochemical properties of gelatin gels from walleye pollock (Theragra chalcogramma) skin cross-linked by gallic acid and rutin. Food Hydrocolloids 2011, 25 (5), 907-914.

41. Spizzirri, U. G.; Iemma, F.; Puoci, F.; Cirillo, G.; Curcio, M.; Parisi, O. I.; Picci, N., Synthesis of Antioxidant Polymers by Grafting of Gallic Acid and Catechin on Gelatin.

Biomacromolecules 2009, 10 (7), 1923-1930.

42. Romero-Montero, A.; del Valle, L. J.; Puiggalí, J.; Montiel, C.; García-Arrazola, R.; Gimeno, M., Poly(gallic acid)-coated polycaprolactone inhibits oxidative stress in epithelial cells. Materials Science and Engineering: C 2020, 115, Article ID 111154.

43. Hlushko, R.; Hlushko, H.; Sukhishvili, S. A., A family of linear phenolic polymers with controlled hydrophobicity, adsorption and antioxidant properties. Polymer Chemistry 2018, 9 (4), 506-516.

44. Zhan, K.; Ejima, H.; Yoshie, N., Antioxidant and Adsorption Properties of Bioinspired Phenolic Polymers: A Comparative Study of Catechol and Gallol. ACS Sustainable Chemistry \& Engineering 2016, 4 (7), 3857-3863.

45. Zhan, K.; Kim, C.; Sung, K.; Ejima, H.; Yoshie, N., Tunicate-Inspired Gallol Polymers for Underwater Adhesive: A Comparative Study of Catechol and Gallol. Biomacromolecules 2017, 18 (9), 2959-2966.

46. Patil, N.; Cordella, D.; Aqil, A.; Debuigne, A.; Admassie, S.; Jérôme, C.; Detrembleur, C., Surface- and Redox-Active Multifunctional Polyphenol-Derived Poly(ionic liquid)s:

Controlled Synthesis and Characterization. Macromolecules 2016, 49 (20), 7676-7691.

47. Pan, X.; Tasdelen, M. A.; Laun, J.; Junkers, T.; Yagci, Y.; Matyjaszewski, K., Photomediated controlled radical polymerization. Progress in Polymer Science 2016, 62, 73-125.

48. Moad, G.; Rizzardo, E., A 20th anniversary perspective on the life of RAFT (RAFT coming of age). Polymer International 2020, 69, 658-661.

49. Perrier, S., 50th Anniversary Perspective: RAFT Polymerization-A User Guide. Macromolecules 2017, 50 (19), 7433-7447.

50. Ferji, K.; Venturini, P.; Cleymand, F.; Chassenieux, C.; Six, J.-L., In situ glyconanostructure formulation via photo-polymerization induced self-assembly. Polymer Chemistry 2018, 9 (21), 2868-2872. 
51. Ikkene, D.; Arteni, A. A.; Song, H.; Laroui, H.; Six, J. L.; Ferji, K., Synthesis of dextranbased chain transfer agent for RAFT-mediated polymerization and glyco-nanoobjects formulation. Carbohydrate Polymers 2020, 234, Article ID 115943.

52. Ikkene, D.; Arteni, A. A.; Ouldali, M.; Six, J.-L.; Ferji, K., Self-assembly of amphiphilic copolymers containing polysaccharide: PISA versus nanoprecipitation, and the temperature effect. Polymer Chemistry 2020, 11 (29), 4729-4740.

53. Lu, L.; Zhang, H.; Yang, N.; Cai, Y., Toward Rapid and Well-Controlled Ambient Temperature RAFT Polymerization under UV-Vis Radiation: Effect of Radiation Wave Range. Macromolecules 2006, 39 (11), 3770-3776.

54. McKenzie, T. G.; Fu, Q.; Uchiyama, M.; Satoh, K.; Xu, J.; Boyer, C.; Kamigaito, M.; Qiao, G. G., Beyond Traditional RAFT: Alternative Activation of Thiocarbonylthio Compounds for Controlled Polymerization. Adv. Sci. 2016, 3 (9), Article ID 1500394.

55. Liu, F.; Long, Y.; Zhao, Q.; Liu, X.; Qiu, G.; Zhang, L.; Ling, Q.; Gu, H., Gallolcontaining homopolymers and block copolymers: ROMP synthesis and gelation properties by metal-coordination and oxidation. Polymer 2018, 143, 212-227.

56. Lertturongchai, P.; Ibrahim, M. I. A.; Durand, A.; Sunintaboon, P.; Ferji, K., Synthesis of Thermoresponsive Copolymers with Tunable UCST-Type Phase Transition Using Aqueous Photo-RAFT Polymerization. Macromolecular Rapid Communications 2020, 41 (9), Article ID 2000058.

57. Li, H.; Li, M.; Xu, R.; Wang, S.; Zhang, Y.; Zhang, L.; Zhou, D.; Xiao, S., Synthesis, structure activity relationship and in vitro anti-influenza virus activity of novel polyphenolpentacyclic triterpene conjugates. European Journal of Medicinal Chemistry 2019, 163, 560-568. 58. Ren, Y.; Himmeldirk, K.; Chen, X., Synthesis and Structure-Activity Relationship Study of Antidiabetic Penta-O-galloyl-d-glucopyranose and Its Analogues. Journal of Medicinal Chemistry 2006, 49 (9), 2829-2837.

59. Rigoussen, A.; Verge, P.; Raquez, J.-M.; Dubois, P., Natural Phenolic Antioxidants As a Source of Biocompatibilizers for Immiscible Polymer Blends. ACS Sustainable Chemistry \& Engineering 2018, 6 (10), 13349-13357.

60. Nomeir, B.; Fabre, O.; Ferji, K., Effect of Tertiary Amines on the Photoinduced Electron Transfer-Reversible Addition-Fragmentation Chain Transfer (PET-RAFT) Polymerization. Macromolecules 2019, 52 (18), 6898-6903.

61. Ikkene, D.; Arteni, A. A.; Ouldali, M.; Francius, G.; Brûlet, A.; Six, J.-L.; Ferji, K., Direct Access to Polysaccharide-Based Vesicles with a Tunable Membrane Thickness in a Large Concentration Window via Polymerization-Induced Self-Assembly. Biomacromolecules 2021, 22 (7), 3128-3137.

62. Poaty, B.; Dumarçay, S.; Gérardin, P.; Perrin, D., Modification of grape seed and wood tannins to lipophilic antioxidant derivatives. Industrial Crops and Products 2010, 31 (3), 509515. 